\section{Outcome of penetrating \\ keratoplasty in patients with bilateral corneal blindness}

R Sinha, M Vanathi, N Sharma, JS Titiyal, $\mathrm{RB}$ Vajpayee and $\mathrm{R}$ Tandon

\begin{abstract}
Purpose To evaluate the outcome of penetrating keratoplasty in patients with bilateral corneal blindness.

Methods Bilaterally blind patients who had undergone optical penetrating keratoplasty (PK) were evaluated on optical and refractive parameters and presence of complications if any. The results at 3 months, 6 months, and 1 year were compared with age-matched and indication-matched unilaterally blind controls.

Results The most common indication for surgery in both the groups was the presence of a corneoiridic scar. Best corrected visual acuity of $\geqslant 6 / 18$ was seen in five $(16.66 \%)$ patients in the study group and in $11(36.66 \%)$

\section{Introduction}

Corneal opacity is a common cause of ocular morbidity in developing countries. ${ }^{1,2}$ In India, one million persons are estimated to be blind in both eyes with corneal disorders, and they add to the burden of stretched medical and financial resources. The outcome of a corneal graft performed in these patients depends upon a number of host and graft factors. ${ }^{3-5}$ In our clinical practice, we observed that the outcome of penetrating keratoplasty in patients with bilateral corneal blindness appears to be different from that in patients with unilateral disease. This study was therefore undertaken to compare the results of keratoplasty in these two categories and identify predictive or prognostic variables that could influence the outcome.
\end{abstract} patients in the control group ( $P=0.14)$. In all, $15(50 \%)$ grafts in the study group and six (20\%) in the control group failed $(P=0.03)$. The most common cause of failure was graft infection $(40 \%)$ in the study group and postPK glaucoma $(20 \%)$ in the control group. The percentage of graft rejection as a cause of graft failure was the same in both the groups.

A composite socioeconomic status scale based on family literacy and income suggested that $70 \%$ of the cases in the study group and $30 \%$ in the control group belonged to the low socioeconomic group $(P=0.004)$.

Conclusion The outcome of optical penetrating keratoplasty in patients with bilaterally blinding corneal disease is poorer than those who are unilaterally blind. Low socioeconomic status may be a contributing factor for the poor outcome.

Eye (2005) 19, 451-454. doi:10.1038/sj.eye.6701534

Published online 20 August 2004

Keywords: keratoplasty; bilaterally blind; corneal graft survival

\section{Method}

A retrospective review of records of patients, who had undergone penetrating keratoplasty in one of their eyes in the cornea and refractive surgery unit of our centre from 1 July 2002 to 31 March 2003, was performed. In all, 30 patients who had bilateral corneal blindness (best corrected visual acuity (BCVA) less than 3/60 on Snellen's acuity chart in the better eye) and had undergone penetrating keratoplasty in one of their eyes and were on regular follow-up were identified and included in the study.

The following optical and refractive parameters of these patients were noted from the records: uncorrected visual acuity (UCVA), BCVA, graft clarity, keratometry and/or corneal topography, anterior chamber depth and presence of inflammatory reaction, intraocular pressure, and fundus evaluation, if possible. The results at 3 months, 6 months and 1 year from the available records were analysed.
Rajendra Prasad Centre for Ophthalmic Sciences All India Institute of Medical Sciences

New Delhi, India

Correspondence: $\mathrm{R}$ Tandon Rajendra Prasad Centre for Ophthalmic Sciences

All India Institute of Medical Sciences

New Delhi 110029 India

Tel: 911126593192

Fax: 911126588919

E-mail: radhika_tan@

yahoo.com

Received: 26 October 2003 Accepted: 23 February 2004 Published online: 20 August 2004

Presented in part at the Annual Conference of the Royal College of Ophthalmologists, UK held in Birmingham from 20 to 22 May 2003 
Table 1 Questionnaire

1. Do you notice any (subjective) improvement in vision?

2. Can you recognize people's faces?

3. Can you move unaided in familiar surroundings?

4. Can you move unaided in unfamiliar surroundings?

5. Can you read/do near work?

6. Can you do your daily routine work?

7. Has it affected your professional life?

8. Has your ability to work improved?

9. Can you drive a vehicle?

10. How do you feel about your graft outcome? - happy/just satisfied/not satisfied

In all, 30 patients with unilateral corneal disease who had undergone penetrating keratoplasty were selected by matching for age and indication for surgery (diagnosis) with the study group and these served as controls.

Patients in the study group and the control group were subsequently interviewed at their next follow-up visits to ascertain factors that we hypothesized could contribute to the outcome of the surgery. In addition, questions were asked to assess the patients' perception of the outcome. Patient satisfaction was judged on the basis of their response to a formulated questionnaire (Table 1).

A composite socioeconomic status scale was formulated on the basis of family literacy and annual income.

\section{Results}

The mean age of the patients was $53.5 \pm 5.37$ years in the study group and $52.71 \pm 6.31$ years in the control group. In all, 24 patients $(80 \%)$ in the study group and 22 patients $(73.33 \%)$ in the control group were males.

The most common indication for surgery in both the groups was corneoiridic scar $(50 \%$ in the study group and $76 \%$ in the control group). In both the groups, this was followed by failed previous graft $(33.33 \%$ in the study group and $13.33 \%$ in the control group) and bullous keratopathy $(16.66 \%$ in the study group and $10 \%$ in the control group). The preoperative BCVA was hand movement near to the face in 27 eyes in the study group and 26 eyes in the control group. Three eyes in the study group and four eyes in the control group could count fingers at $1 \mathrm{~m}$. The projection of rays was accurate in all four quadrants in all the patients in both the groups. At 3 months follow-up, BCVA of $\geqslant 3 / 60$ was seen in 29 eyes in the study group and 30 eyes in the control group (Figure 1). At 1 year follow-up, the BCVA of $>6 / 18$ was seen in five eyes $(16.66 \%)$ in the study group and in 11 eyes $(36.66 \%)$ in the control group $(P=0.14)$ (Figure 2$)$. In all, 16 eyes $(53.33 \%)$ in the study group and seven

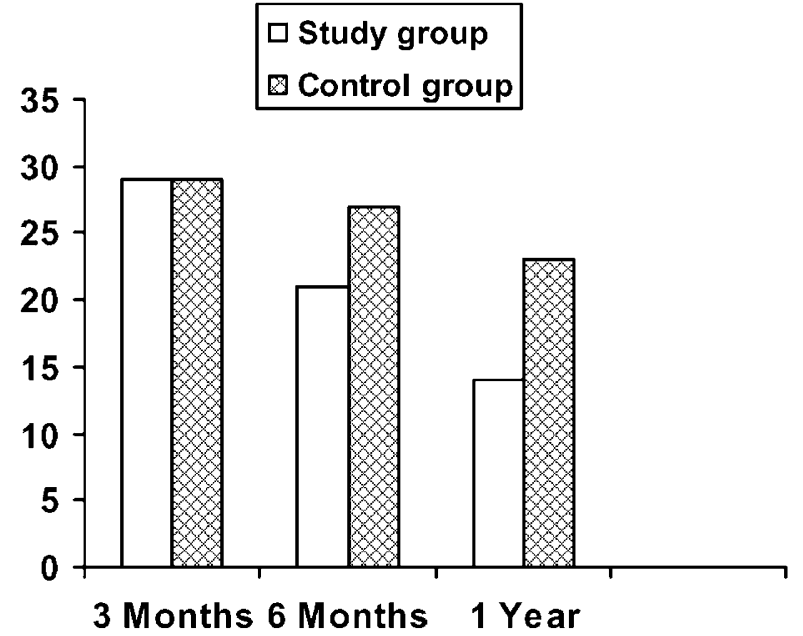

Figure 1 Number of patients with BCVA $\geqslant 3 / 60$.

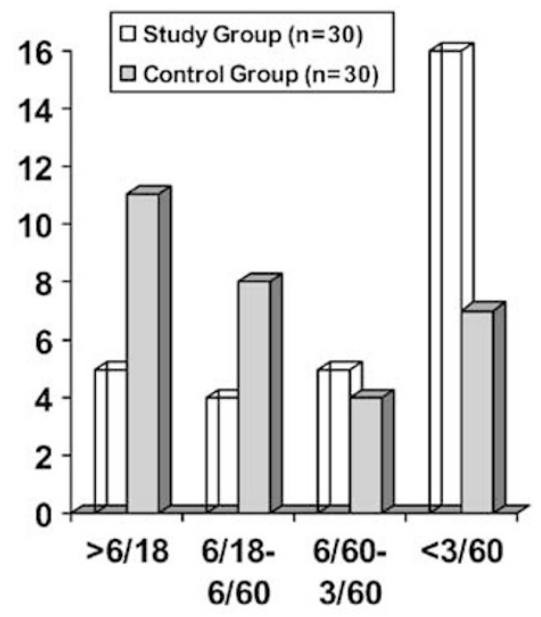

Figure 2 BCVA at 1 year.

eyes $(23.33 \%)$ in the control group had BCVA of $<3 / 60$ at 1 year follow-up.

In all, 15 grafts (50\%) in the study group and six (20\%) in the control group failed $(P=0.03)$ by the end of the first year (Figure 3). The important causes of graft failure were infection ( $40 \%$ in study group, $16.7 \%$ in controls); rejection (26.6\% in study group, $33.3 \%$ in controls) and post-PK glaucoma ( $26.6 \%$ in study group, $50 \%$ in controls).

The causes of subnormal vision in eyes with clear grafts were high astigmatism, pre-existing glaucoma, active or resolved macular oedema, macular scar, partial optic atrophy, and coexisting diabetic maculopathy.

In all, 13 patients in the study group were happy with the graft outcome; five patients were just satisfied and 12 patients were not satisfied. In the control group, seven 


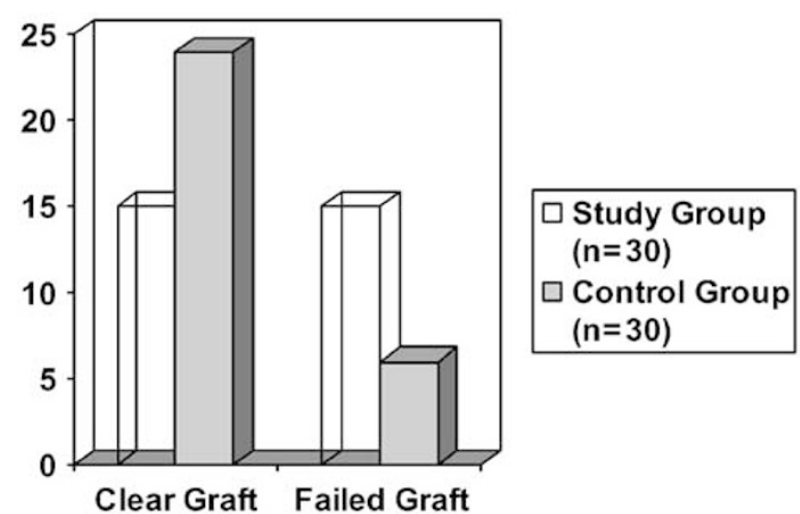

Figure 3 Outcome of PK after 1 year.

patients were happy; nine patients were just satisfied and 14 patients were not satisfied.

In all, $70 \%$ of the cases in the study group and $30 \%$ in the control group were graded to be of low socioeconomic status $(P=0.004)$.

\section{Discussion}

Blinding eye diseases are highly prevalent in many developing countries, where the prevalence of blindness has been estimated to be ten to forty times higher than in industrialised countries. ${ }^{1}$ Corneal blindness, particularly bilateral is a major cause of visual handicap, particularly in third-world countries owing to a high incidence of corneal infection and ulceration.

Outcome of corneal transplantation depends on a number of factors. There are only a few published studies of long-term visual outcome in cohorts of patients with mixed indications for graft. ${ }^{6,7}$ To the best of our knowledge, there is no published study in which a comparative evaluation of visual outcome of penetrating keratoplasty in bilateral and unilateral corneal blind has been performed.

In the present study, the BCVA at 1 year after corneal transplantation was corresponding to the status of the graft. Understandably, the BCVA was poorer in the study group due to high percentage of graft failure. For a corneal graft procedure to be of benefit to the majority of patients undergoing corneal transplantation, a number of conditions must be met. The grafted eye must be capable of visual perception, that is, there must be no serious disorder affecting the retina, optic nerve, or higher visual processing centres.

Hospital-based data on the survival of corneal grafts performed at a reputed eye institute in India showed that the 5-year survival rate for corneal transplants performed for the first time was $46.5 \%$ for all pathologies causing corneal blindness considered together. ${ }^{8}$ Some of the indications for keratoplasty in this study had particularly dismal 5-year survival rates: $31.5 \%$ for adherent leucomas, and $21.5 \%$ for aphakic bullous keratopathy. ${ }^{8}$ In the present study, overall graft survival at 1 year was $50 \%$ in the study group and $80 \%$ in the control group, with the most common indication for surgery in both the groups being adherent leucoma. Graft survival was not as good in the study group as compared to the controls and there was a statistically significant difference in the graft survival between the two groups. The most common cause of graft failure in the study group was graft infection. This was attributable to poor personal hygiene and infection related to loose sutures.

In the initial follow-up period, most of the patients in both the groups had better than ambulatory vision in the operated eye. However, in the later postoperative phase, there was a decline in the BCVA. This was most likely because the frequency of follow-up reduced and complications could not be detected promptly in their early stages. This led to the development of irreversible sequelae resulting in graft failure and poor visual acuity. Graft failure resulting from these complications was more pronounced in the study group. Majority of the patients in the study group belonged to the low socioeconomic group. Ignorance among people of low socioeconomic group in relation to personal hygiene and eye care and inability to recognize the importance of potentially serious symptoms of the complications can be the reason for inappropriate care of the corneal graft. The high percentage of graft failure in the study group as compared to the control group appears to have a direct relationship with the higher proportion of patients of low socioeconomic status. This is in accordance with other studies that report that patients belonging to a lower socioeconomic status had $28 \%$ higher risk of corneal graft failure, and also had a 2.5 times higher chance of infection causing graft failure., 8

The prevalence of blindness due to corneal disease has been shown to be higher in the uneducated population and in those belonging to extremely low socioeconomic strata. ${ }^{2,10}$ We have personally observed that patients with bilateral corneal opacities are more disadvantaged in terms of income and education and are also more prone to graft failure.

The outcome of corneal transplantation should be considered in light of the patients' perceptions of success, which itself may be related to pregraft expectations and attitudes towards disability, acceptance of the prescribed correction (especially contact lens), and the visual function of the contralateral eye as well as the measured visual acuity in the graft. The achievement of patient satisfaction at the completion of surgery and any subsequent rehabilitation depends on the interaction of many interconnected factors. Identification of these 
factors necessarily requires a somewhat broader approach than the straightforward measurement of visual acuity. ${ }^{11}$

To summarize, the overall objective outcome of penetrating keratoplasty in the present study has been demonstrated to be poorer in bilaterally blind persons. However, patient satisfaction was higher in this group than those with unilateral corneal blindness. As the patients in the study group were bilaterally blind before keratoplasty, any vision that could make them even just ambulatory was very satisfying to them as they could now lead an independent existence and manage their day-to-day activities.

\section{References}

1 Thylefors B, Negrel AD, Pararajasegaram R, Dadzie KY. Global data on blindness. Bull World Health Organ 1995; 73: 115-121.

2 Dandona R, Dandona L. Corneal blindness in a southern Indian population: need for health promotion strategies. Br J Ophthalmol 2003; 87: 133-141.

3 Vail A, Gore SM, Bradley BA, Easty DL, Rogers CA. Corneal graft survival and visual outcome. A Multicenter Study.
Cornea Follow-up Study Collaborators. Ophthalmology 1994; 101: $120-127$.

4 Volker-Dieben HJ, D'Amaro J, Kok-Van Alphen CC. Hierarchy of prognostic factors for corneal allograft survival. Aust NZ J Ophthalmol 1987; 15: 11-18.

5 Williams KA, Roder D, Esterman A, Muehlberg SM, Coster DJ. Factors predictive of corneal graft survival Report from Australian Corneal Graft Registry. Ophthalmology 1992; 99: 403-414.

6 Stulting RD, Sumers KD, Cavanagh HD, Waring GO 3rd, Gammon JA. Penetrating keratoplasty in children. Ophthalmology 1984; 91: 1222-1230.

7 Jager MJ, Hermans LJA, Kok JHC. Visual results after corneal transplantation. Doc Ophthalmol 1989; 72: 265-271.

8 Dandona L, Naduvilath TJ, Janarthanan M, Ragu K, Rao GN. Survival analysis and visual outcome in a large series of corneal transplants in India. Br J Ophthalmol 1997; 81: 726-731.

9 Dandona L, Naduvilath TJ, Janarthanan M, Rao GN. Causes of corneal graft failure in India. Indian J Ophthalmol 1998; 46: 149-152.

10 Dandona R, Dandona L. Socioeconomic status and blindness. Br J Ophthalmol 2001; 85: 1484-1488.

11 Williams KA, Ash JK, Pararajasegaram P, Harris S, Coster J. Long term outcome after corneal transplantationVisual result and patient perception of success. Ophthalmology 1991; 98: 651-657. 